\title{
PREFERIRÍA NO HACERLO: ARQUITECTURAS DE BARTLEBY
}

\author{
José Manuel López UjaQue \\ Arquitecto y Doctorando ETSAM Madrid \\ https://dx.doi.org/10.12795/astragalo.2016.i21.07
}

En el relato de Melville ${ }^{1}$, Bartleby repite en diez momentos su célebre y enigmática frase: Preferiría no hacerlo. Su historia es la de un abogado neoyorquino que decide contratar a un nuevo copista para su oficina, ya que los otros dos que tenía contratados no podían hacer frente a todo el trabajo existente. Ante esta situación el abogado decide publicar una oferta de trabajo en un periódico local, es aquí cuando Bartleby entra en escena y es contratado de manera inmediata. Al principio, Bartleby se muestra como un empleado ejemplar, sin embargo a partir de cierto momento empieza a declinar cualquier tipo de actividad que le proponga su jefe usando repetidamente la frase Preferiría no hacerlo (I would prefer not to en el texto original en inglés). Desde ese momento el abogado no sabe cómo actuar y tomarse la respuesta de su empleado, pasado por todo tipo de estados y pensamientos al respecto. La historia acaba de manera convulsa, y podríamos decir que triste, pero lo relevante aquí es esa frase que Bartleby repite obsesivamente a modo de mantra personal y que ha dado pie a todo tipo de interpretaciones. De entre ellas resultan interesantes las que realizan los filósofos Gilles Deleuze ${ }^{2}$, Giorgio Agamben ${ }^{3}$ y José Luis Pardo ${ }^{4}$.

Deleuze es categórico cuando afirma que I would prefer not to, no es una afirmación ni una negación ${ }^{5}$, establece así que la enigmática respuesta de Bartleby se mueve en un intervalo fronterizo borroso. Si su respuesta hubiera sido un 'sí' podríamos entender que declaraba su total sumisión al trabajo, a hacer caso a su jefe y sus órdenes, a seguir las reglas; si su respuesta hubiera sido un 'no' podríamos tildarlo de contestatario, de abandonarse a esa pereza dolorosa de la que hablaba Barthes en su texto Atrevámonos a ser perezosos ${ }^{6}$. 
Pardo insiste en esa importante condición activa y positiva de Bartleby. La preferencia negativa no es, pues, una preferencia nihilista (elegir la nada en vez de algo) sino la elección positiva ${ }^{7}$. Bartleby no es Oblómov ${ }^{8}$ (el personaje de Goncharov), ni tampoco un calco del Guy Debord más joven y contestatario escribiendo en un muro parisino ne travaillez jamais.

Agamben solapa sus reflexiones con las de Deleuze y Pardo y añade el avance como otro punto que se desprende de la actitud positiva de Bartleby. Jaworski, por su parte, ha observado que la fórmula no es afirmativa ni negativa, que Bartleby no acepta ni rechaza sino que avanza y se retira en su mismo avanzar; es decir, tal y como sugiere Deleuze, que abre una zona de indiscernibilidad entre el

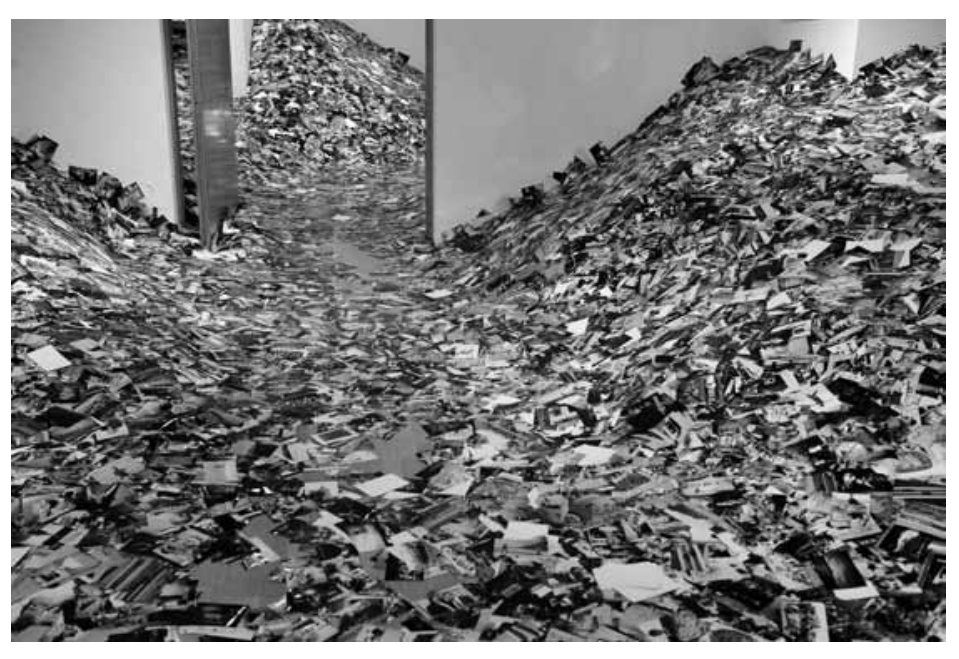
sí y el no, entre lo preferible y lo no preferido [...] Una fórmula que se mantiene a medio camino entre la afirmación y la negación, entre la aceptación y el rechazo, entre el poner y el quitar ${ }^{9}$.

\section{DESTACAR EN LA SOBREABUNDANCIA}

En este sentido obras artísticas como 24 hours of Flickr del fotógrafo holandés Erik Kessels enlazan con la actitud de Bartleby y su preferencia de avance positivo sobre el no hacer. Kessels prefiere no hacer más fotos, decide imprimir un día de 2011 todas las fotos subidas durante un periodo de veinticuatro horas a la comunidad de internet Flickr (especializada en fotografía), el resultado es una enorme montaña de docu- mentos gráficos que inunda salas de museos. La obra es una postproducción ${ }^{10}$ tal como la define Nicolas Bourriaud y que habla de dos condiciones: por una parte del carácter entrópico de la sociedad en la que estamos inmersos, y por otra de la desaparición de la originalidad o especificidad (ninguna foto destaca sobre otra en ese magma inabarcable).
Situaciones como esta son examinadas con tremenda precisión por el también fotógrafo Joan Fontcuberta, resultando especialmente didáctico y esclarecedor su texto Por un manifiesto posfotográfico dónde hace hincapié en la época de banda ancha que estamos viviendo: Desde un punto de vista de los usos, se trata de una revolución comparable a la instalación de agua corriente en los hogares en el siglo XIX. Hoy disponemos a domicilio de un grifo de imágenes que implica una nueva higiene de la visión ${ }^{11}$. ¿Para qué hacer más fotografías cuando hay ya millones en la red? El autor ya no crea sino que selecciona.

Volviendo al hilo anterior surge un punto de duda: ¿Cómo destacar en ese vasto 
sustrato? ¿Qué es más radical? ¿Intentar añadir una foto más que destaque entre el ruido de las miles de la instalación de Kessels? ¿Sería más notorio y eficiente simplemente introducir una foto vacía, silenciosa? ¿Una foto vacía a lo Bartleby?

Como caso paralelo, y para comenzar a introducir ejemplos arquitectónicos, vienen a colación dos imágenes que Rem Koolhaas utiliza recurrentemente. Cuenta que en 2005 le encargaron diseñar un edificio dentro de la ingente cantidad de rascacielos existentes y por existir en el skyline de Dubai. La respuesta directa hubiera sido sumergirse en ese ruido de edificaciones intentando hacer otra más alta, más cara y más espectacular, pero ¿cómo destacar realmente en ese paisaje? ${ }^{12}$ Su respuesta fue ser radical -según sus propias palabras-y proponer un enorme bloque neutro de hormigón blanco de 200 metros de ancho y 300 de alto que destacaba por oposición y neutralidad entre el resto de edificios - del mundo- pero que seguía aumentando la serie infinita de tales construcciones. radical. Hacer casi nada se convierte en la intervención más poderosa. Sin embargo, los arquitectos están tan acostumbrados a oír la palabra «no» que tienen miedo de usarla ellos mismos. La poderosa arma de hacer nada o, mejor aún, casi nada, se abandona en favor de la eficaz rutina inmovilista de añadir un poco más dentro de ya un montón ${ }^{3}$.

¿Qué hubiera sido más radical? ¿Y si Koolhaas hubiera decidido resolver el proyecto a través de no hacer nada o casi nada? ¿Hubiera generado eso un ruido realmente audible, un acto realmente radical?

\section{ATREVÁMONOS A SER PEREZOSOS... Y SILENCIOSOS}

La postproducción, tal y como la entendemos hoy en día, ya no es un acto radical que genere extrañamiento. En mayor o menor medida todos hemos interiorizado, gracias al desarrollo digital en el que estamos inmersos, los proce-

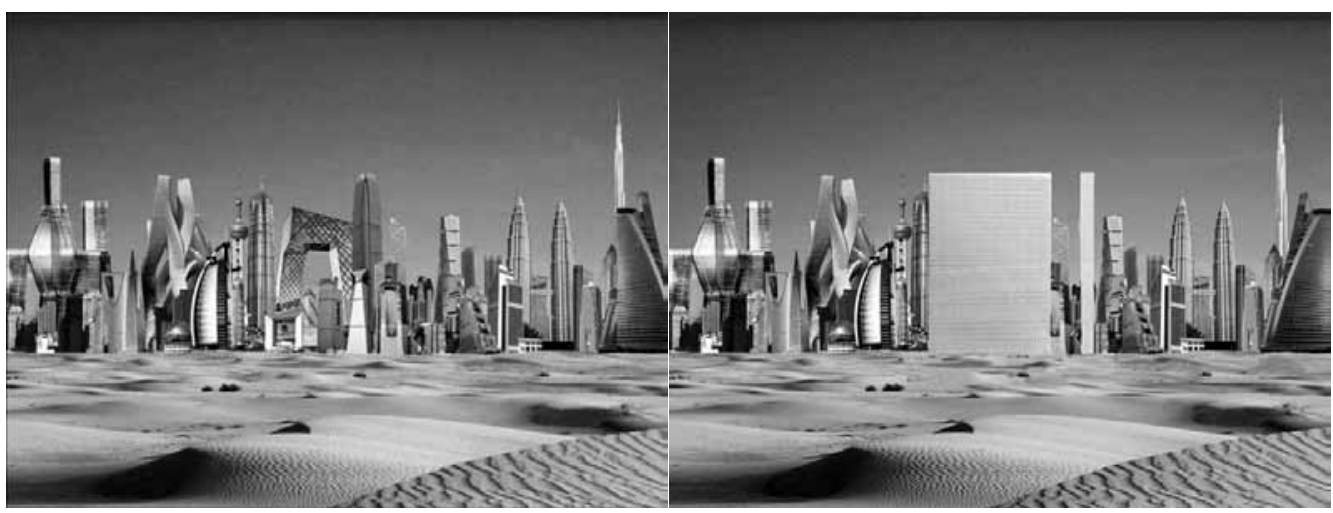

Un edificio ruidoso en un ambiente ruidoso no emite ningún ruido audible. De la misma manera, hacer poco puede ser hacer mucho y hacer nada puede ser un acto sos relacionados con cortar, copiar o pegar; y pronto las nuevas generaciones nativas digitales también serán nativas postproductivas, no conocerán qué significa producir nuevos materiales. 
Es cierto que los procesos postproductivos contemporáneos siguen suponiendo una declinación tal y como la explicaba José Luis Pardo refiriéndose a Bartleby, un lugar agramatical entre el sí y el no alejado tanto del nihilismo - pues no se cruza de manos- como del amor al trabajo - pues rechaza generar nuevas materias primas-. Sin embargo, y esto es algo que el propio Bourriaud expone en su texto hablando de la neutralidad con que los artistas contemporáneos utilizan la postproducción: Los artistas ejecutan actualmente la postproducción como una operación neutra, de suma cero, allí donde los situacionistas tenían por objeto corromper el valor de la obra desviada, es decir, combatir el capital cultural ${ }^{14}$. Incluso llega tildar de banalidad el uso que determinados artistas hacen de ella: [...] las recientes tendencias musicales han banalizado el desvío ${ }^{15}$.

Es interesante a partir de aquí comenzar a reflexionar sobre una postproducción cuya dirección no tiende hacia el infinito -como la que entendemos comúnmente y la que disecciona Bourriaud- sino de una postproducción que tienda a reducir más y más su injerencia y que introduzca una nueva característica: el silencio. La postproducción entendida como un proceso que tiende a cero recuperaría ese carácter premeditadamente radical, y aplicada así de forma directa al mundo arquitectónico resonaría con total afinidad con las palabras previas de Mark Wigley situadas junto a las imágenes de Koolhaas: Hacer casi nada se convierte en la intervención más poderosa ${ }^{16}$.

\section{EL SILENCIO}

Al igual que el mundo soporta muy mal las actitudes neutras ${ }^{17}$ como decía Barthes acerca de la pereza, también soporta muy mal las actitudes silenciosas. En un mundo dominado por la comunicación y las redes sociales, callar es un mal irremediable ya que mostrarse y hacerse visible parece algo innegociable. El libro del sociólogo y antropólogo francés David Le Breton titulado El silencio disecciona de forma precisa estas y otras connotaciones: Hay en principio en las relaciones sociales occidentales y especialmente en los ritos de la conversación: un deber implícito de hablar, que hace que cualquier reticencia provoque de inmediato un gran desconcierto en los presentes ${ }^{18}$.

La lectura del citado texto permite avanzar sobre la capa superficial del término, superarla, para entenderlo con una mayor complejidad y verosimilitud. Se puede observar como entran en juego otros factores. Culturalmente, el silencio alcanza diversas dimensiones en función de su localización. La definición negativa que adoptamos del silencio es eminentemente occidental, e incluso dentro de dicho ámbito, los matices son variados y heterogéneos. Para una sociedad que hiciese virtud del silencio o de la sobriedad de la palabra, lo sorprendente no sería tanto el mutismo de Bartleby como la obsesión de los que le rodean por hacerle hablar. No hay 'silenciosos'o 'locuaces' más que en función del estatuto cultural del discurso. Las reglas sociales de participación implican un régimen de palabras específico para un grupo, y para las diversas situaciones de la vida en común, y exigen del individuo que se someta sin trabas a las reglas implícitas del intercambio. La distribución del silencio y de la palabra en la conversación responde a un estatuto social y cultural que cambia de un lugar a otro y de un tiempo a otro; y también varía según las situaciones y sus protagonistas. [...] En los países escandinavos, por ejemplo, inundar un encuentro con un turbión de frases incesante para luchar contra el silencio no tendría una buena acogida ${ }^{19}$. 
Esta situación ahonda en hacernos pensar que, tanto establecer un sentido positivo del silencio como de la pereza -o de esa pereza silenciosa demandada para insuflar otra vez radicalidad y premeditación a la postproducción-implica escaparse de la imposición cultural y geográfica predominante, ser excéntrico. En este caso escapar de un entendimiento occidental negativo dónde no hablar o no hacer es considerado algo muy perturbador.

La otra creencia superficial es que el silencio total, la negación total, existe y es posible; puesto que refutarlo sería contradecir el propio significado de ausencia del término. Quedarse en esa visión superficial sería otra vez apostar por una vertiente nihilista, pasiva y negativa de la negación. El músico experimental John Cage, en busca de ese silencio total, consiguió demostrar lo diametralmente opuesto y se encargó de tirar por tierra dicha concepción a través de sendas experiencias sonoras. De hecho Cage acabaría definiendo el silencio como La presencia de sonido ambiente o ruido inintencionado en vez de la completa ausencia de sonido ${ }^{20}$.

Ambas experiencias han sido publicadas y estudiadas hasta la saciedad. En la primera (1951) entró en la cámara anecoica ${ }^{21}$ de la universidad de Harvard en busca del silencio. Por el contrario, descubrió que por encima del silencio total estaban, en ese silencio próximo o tendente a cero, los sonidos de su corazón bombeando sangre y el zumbido incesante de su sistema nervioso. El silencio era imposible, no existía, era solo un concepto abstracto. En la segunda experiencia, la obra musical 4'33", Cage compuso una partitura donde no sonaba ningún instrumento y durante 4 minutos y 33 segundos la orquesta y su director permanecían quietos. Esta obra, que sonó por primera vez en 1952 en Woodstock, provocaba la incomodidad del público y ponía en valor sonidos accidentales como los movimientos incómodos en la silla o los estornudos inoportunos de los espectadores. Otra prueba que refutaba la existencia del silencio total.

Cuando una persona se calla, no por ello deja de comunicar ${ }^{22}$ Los silencios que aquí interesan son esos otros silencios activos y proyectivos, Interesan esos silencios que no llegan a serlo, que se mueven en ese umbral de lo infraleve ${ }^{23}$, en ese umbral donde los silencios -como ya ha quedado demostrado- no existen. Esos silencios que no niegan, sino que declinan y con ello generan un estado de avance y no un estado de pausa.

Podríamos especular y aplicar directamente esa condición de silencio a la actitud postproductiva contemporánea y así convertirla en una situación que ya no solo tienda hacia el infinito -hacia la creación de más materiales culturales- sino también a cero en ciertas ocasiones. Este desplazamiento hacia el polo opuesto, hacia tender a cero, la convierte en una acción realmente poderosa alejada del ruido que genera la postproducción común actual de carácter exotérmico - de un esfuerzo creciente y externo-, para volver a convertirla en un acto radical de carácter endotérmico - de un esfuerzo decreciente e interno-.

\section{HACER (CASI) NADA EN ARQUITECTURA}

La evolución de la actitud perezosa, o del no hacer, dentro de la práctica arquitectónica ha sufrido históricamente el mismo rechazo que en el resto de disciplinas o facetas vitales. La pereza es un mal cuya situación se agrava den- 
tro de la arquitectura, teniendo en cuenta que ha sido una disciplina donde el hacer ha sido el único elemento validador dentro de la carrera profesional de cualquier arquitecto. ¿Un arquitecto que no construye puede ser considerado como un arquitecto? Se podría decir que una idea así implica el suicidio de la arquitectura más que su renovación estética [...] comienza diciendo el arquitecto Iñaki Ábalos en su artículo Bartleby, el arquitecto, sin embargo continúa [...] pero hay ejemplos como el del estudio francés Lacaton \& Vassal que muestran que no es asi ${ }^{24}$.

La connotación negativa que pueda llegar a tener el término ha sido ya superada por toda una serie de personajes, no sólo Lacaton \& Vassal. No es un suicidio, no es una quimera puesto que de momento una idea ha calado hondo en los primeros debates entre los expertos. La idea de que Bartleby, el personaje creado por Melville, y su famoso 'preferiría no hacerlo' es quien mejor expresa la dimensión estética de la sostenibilidad cuestionando la necesidad misma de toda acción (una idea ya expresada hace años por (edric Price) $)^{25}$.

Estos personajes y algunos de sus proyectos -no todos- formarían parte de una especie de sociedad perezosa secreta, a imagen y semejanza de los shandys ${ }^{26}$ o portátiles de Vila-Matas en su libro Historia de la Literatura Portátil. Al igual que los portátiles respondían a una serie de requisitos ${ }^{27}$ indispensables, estos arquitectos perezosos deben intentar:

1- Mostrarse excéntricos frente a la cultura arquitectónica en la que se encuentran inmersos.

2- Hacer del intervalo agramatical su lugar de confort y de trabajo.

3- Desespecializarse con premeditación frente a las derivas hiperactivas existentes.

4- Desaparecer como autores.

Sin embargo, su sociedad es secreta e inconfesable; no se reconocen abiertamente como tal debido al miedo a que su actividad silenciosa sea descubierta, sus declaraciones los delatan: No puedo decir que en 'Palais de Tokyo' utilizáramos una actitud de no hacer nada ${ }^{28}$.

\section{MIEDO AL HACER (CASI) NADA}

Si quieres convertirte en un arquitecto creativo, no sólo debes ser capaz de hacer cualquier cosa, también tienes que hacerla. Trabajar, trabajar, trabajar: ese es el lema ${ }^{29}$, escribe el crítico Ole Bouman con ironía. El miedo a ser descubiertos parte de esa condición implícita de la arquitectura que es el construir. Además, tal miedo a declararse como no constructores -en determinados proyectos- se ve acrecentado por una especie de fanatismo instaurado que opera en sentido contrario. Al día de hoy no sólo hay que hacer, sino que cada proyecto debe ser más espectacular que el anterior y así sucesivamente hasta el infinito. Como bien apunta Mark Wigley Sin tener mucho que hacer, los arquitectos suelen hacer demasiado. [...] Tratan cada proyecto como si fuera el último, convirtiéndolo en un arca cargada con sus mejores ideas reunidas en un intenso despliegue de efectos. Tales edificios actúan como eficientes dispositivos de emisión, proyectores que lanzan continuamente un aluvión de imágenes como si fueran misiles. Los proyectos se convierten en misiles y la calidad arquitectónica se juzga por el número de imágenes que son capaces de difundir por el mun$d o^{30}$. Se produce una huida hacia adelante del 
problema, en el sentido que es preferible avanzar, construir más, en vez de pararse a evaluar si cada nueva construcción en necesaria o no.

En un mundo ya repleto donde el croquis inicial sobre un folio en blanco se ha transformado en la manipulación de un material existente ${ }^{31}$ quizás habría que valorar como mínimo la necesidad misma de actuar y perder ese miedo dentro de los arquitectos a verse identificados con profesionales que hacen nada.

Tradicionalmente su profesión estaba enfocada a realizar un servicio y mostrarlo, sobre todo mostrarlo ya que como apunta Wigley eso es lo que hacía verosímil su esfuerzo. Ante esta situación existe un miedo a la inacción dentro de la profesión ${ }^{32}$ y es paradójico que incluso aquellos proyectos que podrían ser clasificados como soluciones que hacen nada difícilmente son reconocidas como tal por los arquitectos responsables.

Puede que el fanatismo de los arquitectos - una miopía que les ha llevado a creer que la arquitectura no es sólo el único medio para todo lo que es bueno, sino también para la explicar lo que es malo-sea no solo una deformación profesional, sino también una respuesta al horror de la arquitectura diferente, un rechazo instintivo hacia el vacio, un miedo a hacer nada ${ }^{33}$. Existe un miedo al vacío, a la no existencia de imágenes finales que se transforma en un fanatismo defensor de los preceptos clásicos de una profesión que debe ampliar sus campos de acción para caminar junto a una sociedad mucho más inmaterial.

¿Por qué los arquitectos no pueden dejar de construir y seguir considerándose arquitectos? Deberíamos exigir cierta rebeldía por parte de los arquitectos contemporáneos.

\section{EL ARQUITECTO REBELDE}

¿Qué es un hombre rebelde? Un hombre que dice que no. Pero si se niega, no renuncia: es además un hombre que dice que sí desde su primer movimien$t^{34}$. Llegados a este punto, la primera frase que escribe el filósofo Albert Camus en su libro El hombre rebelde cobra mucho sentido puesto que recoge todas las condiciones examinadas de la pereza. Utiliza el adjetivo rebelde al igual que esa actitud rebelde demandada para que -a través de transformaciones silenciosas- el arquitecto silencioso vuelva a cargar de significado su trabajo postproductor apartándolo de la neutralidad actual. Y ese hombre dice no, pero si se niega no renuncia, dice sí, se sitúa en ese territorio agramatical donde la pereza adquiere un carácter tremendamente positivo y activo que es seguido de desespecialización y desaparición.

El carácter propositivo de esta rebeldía, esta pereza positiva, es todo lo que necesitan los arquitectos para avanzar frente al miedo que los atenaza a hacer (casi) nada. Federico Soriano ya lo anticipó manipulando las palabras de Camus: ¿Qué es un [arquitecto] rebelde? Un [arquitecto] que dice no. Pero si se niega, no renuncia: es además un [arquitecto] que dice sí desde su primer movimiento ${ }^{35}$.

Desde este viraje, la figura del arquitecto pasaría a reconocer positivamente y sin miedo su capacidad de resolver ciertos proyectos mediante ese hacer nada. Esto es algo que explica a la perfección el arquitecto Jacobo García-Germán dentro de un capítulo de su Tesis Doctoral: Por tanto la figura del arquitecto que trabaja "por negación» no será tanto la no tan inusual correspondiente a aquel profesional que selecciona cuidadosamente sus encargos de manera que estos se adapten a sus habilidades y favorezcan 
a su lucimiento personal [...]"36 -lo cual encajaría más dentro del fanatismo y miopía que existe en la profesión- [...] sino que se acercará más a aquella que desborde los límites disciplinares para cuestionar la propia necesidad de arquitectura tal y como tradicionalmente se entendió e instalarse en la duda productiva que le permita imaginar futuros alternativos. Lejos de asemejarse a un diletante $o$ amenizador cultural, este arquitecto establece unas pausas de acción que no pasan necesariamente o exclusivamente por una respuesta formal, estética o diseñada sino que prepara previamente un terreno de discusión para facilitar la aparición de un resultado casi invisible, borroso con la realidad en que se instala ${ }^{37}$.

Destaca la condición de no caer en ser un diletante o amenizador cultural. Esta posición podría resonar con las prácticas de ciertos colectivos de arquitectura actuales, en las que los procesos silenciosos y perezosos se confunden con la espontaneidad o el que lo hagan (participen) otros. En dichas prácticas la especificidad del arquitecto y su profesión desaparecen en favor de un pretendido amateurismo y una forzada cercanía que tanto gancho tienen en la sociedad actual. Es otra opción, pero en el fondo supone una banalización en el entendimiento sobre los procesos perezosos desde el punto de vista de un arquitecto; una banalización más cercana al rechazo de la profesión como tal, que a la búsqueda de excentricidad dentro de ella.

Por otro lado expone la preparación de un terreno de discusión que redunda en la condición de desespecialización premeditada del arquitecto perezoso. En dicho terreno se produce una evaluación precisa de las situaciones, de los supuestos silencios, previo paso a establecer cualquier valoración o actuación mínimo a través de la desaparición del sujeto-autor.
La utilización de un resultado casi invisible insiste en la necesidad de utilizar el adverbio casi como representación sintáctica de esa necesaria tendencia a cero de esta actitud, pero no cero absoluto. Necesaria porque es solo en ese intervalo donde la pereza positiva -y no la pasiva- existe.

Y finalmente la condición de instalarse, la realidad en la que se instala. Esta condición incide en una condición inherente al hacer nada, la necesidad de entender sus actuaciones como instalaciones como agregados de capas sobre lo preexistente.

\section{CANTIDAD TENDENTE A CERO}

Mark Wigley apunta como la aparición rebelde en la actualidad de casos arquitectónicos de hacer nada enlaza con una historia de cantidades dentro de la arquitectura. Cada fase de la historia de la arquitectura se define por su particular teoría de la cantidad ${ }^{38}$, estableciendo que en la actualidad la cantidad se ha disparado hacia el infinito, hacia un momento de arquitectura de banda ancha ${ }^{39}$ donde el tamaño de las imágenes, audiencia, flujo, densidad, frecuencia, resolución colores, canales, bits, hilos de noticias, fotogramas por segundo... ${ }^{40}$ nos inundan.

En dicho entorno ruidoso, cómo ya se expuso con anterioridad con el ejemplo de Koolhaas en Dubai, añadir otro edificio ruidoso no genera ningún tipo de ruido que destaque; tan sólo se convierte en molesta palabrería tal y como la explica David le Breton en relación al hablar por hablar por miedo al silencio.

Ante esta situación la figura del arquitecto rebelde surge como una contestación sin miedo a la constante sobrexposición y sobre elaboración de la arquitectura. Emerge, según 
Wigley, como una nueva y extrema forma de minimalismo -jugando con las terminologías sobre cantidades y la cantidad mínima- o de minimalismo que tiende hacia el extremo opuesto, hacia cero. El minimalismo, derivado del arte conceptual de los años 60, es en el fondo solo el anhelo lujoso de una imagen sin importar los esfuerzos necesarios. El «casi nada» minimalista y el concepto de «exceso" no son por tanto fundamentalmente diferentes ${ }^{41}$ desde el punto de vista de la cantidad, ambos demandan de esfuerzos enormes.

Por el contrario, esa arquitectura perezosa del arquitecto rebelde, ese minimalismo extremo de Wigley, parte de un entendimiento de la cantidad totalmente opuesto y de tendencia a cero. Tendente y no cero, puesto que llegar al cero absoluto sería abandonarse en la renuncia y la negación nihilista, y con ello obviar el carácter positivo y arquitectónico demandado por estos personajes pertenecientes a la sociedad perezosa secreta.

Una arquitectura que asume su condición como un vehículo de significado y de servicio inevitablemente «low-medium» en palabras de Wigley. Es decir de bajo perfil, orientada a recuperar su función de neutralidad e indiferencia no mediante la demostración del esfuerzo destinado a conseguir esa neutralidad (el minimalismo), sino mediante la eliminación de dicho esfuerzo ${ }^{42}$.

\section{FALSAS CANTIDADES}

La comparación entre minimalismo y hacer nada establece una historia opuesta a la de Wigley, una historia sobre las falsas cantidades dentro de la arquitectura.

Leon Battista Alberti definía la belleza clásica como un equilibrio de cantidades, ese punto en que nada podía ser añadido pero tampoco quitado para conseguir un efecto. Era una suma de resultado cero en que el mínimo y el máximo eran iguales pero de sentido contrario. El arquitecto era un personaje cuya misión consistía en quitar lo que sobraba para añadir solo lo que faltaba.

La situación contemporánea, como bien explicaba Wigley, ha direccionado la situación arquitectónica hacía una posición de banda ancha donde el mínimo ha desaparecido y solo existe el máximo. Desde ese punto de vista aparecen una serie de comportamientos que hacen la de la falsedad su modo de operar, intentando camuflar bajo una imagen de bajas cantidades, procesos que requieren innegablemente de enormes cantidades.

Uno de los máximos prestidigitadores modernos sobre cantidades es Mies van der Rohe y su weniger ist mehr -menos es más- o su beinahe nichts ${ }^{43}$-casi nada- refiriéndose al planteamiento de su conocidísima casa Farnsworth. Comienza aquí esa condición del minimalismo arquitectónico cuya realidad es en realidad maximalista, puesto que conseguir una imagen de cantidad mínima suponía esfuerzos de construcción máximos, de más y más. La imagen a la aspiraba Mies de unos edificios mínimos en el límite de la materialidad tangible, necesitaban de detalles y técnicas máximas opuestas a dicha condición mínima.

Esta es una situación que no sólo Wigley detecta, sino que el crítico inglés Rayner Banham ya la apuntaba en su texto On trial 6: Mies van der Rohe. Almost nothing is too much aparecido en 1962 dentro de Architectural Review. En dicho texto explicita la disfunción que aparece entre el Mies que piensa menos es más y el Mies que acaba ejecutando sus obras de igual manera 
que lo haría otro arquitecto convencional, no existe ninguna contaminación entre sus pensamientos y materializaciones físicas. Es esclarecedor, por poner un ejemplo, cuando Banham habla del cordón de silicona de la capilla del IIT -Illinois Institute of Technology- Las informes rebabas de masilla negra junto a los montantes de los vidrios de la Capilla del Campus del IIT dejan claro que existen ocasiones donde casi nada no es suficiente $e^{44}$.

Al menos es más le seguirían, en un proceso evolutivo, otros lemas o gritos de guerra que ahondaban -y ahondan todavía hoy- en la adquisición paulatina de la banda ancha por parte de la práctica arquitectónica contemporánea:

Casi nada - Mies van der Rohe $-1946^{45}$

Casi nada es mucho - Reyner Banham - 1962

Menos no es más, menos es aburrido - Robert Venturi - 1968

Más y más, más es más - Rem Koolhaas - 2002

Sí es más - Bjarke Ingels - 2009

Del menos se pasa definitivamente al más.

Sin embargo, sigue siendo relevante como los proyectos que a día de hoy que se reconocen abiertamente como proyectos de menos -en contraposición a ese miedo a reconocerse como tales de los verdaderos arquitectos perezosos y sus proyectos- en el fondo sufren el mismo mal de las falsas cantidades antes expuesto, son herederos de la falsedad del minimaismo.

El máximo exponente del minimalismo como práctica arquitectónica contemporánea, el inglés John Pawson, es un ejemplo manifiesto de todo lo expuesto. Él mismo no tiene ningún reparo en reconocerse admirador de Mies van der Rohe, de los dos grandes arquitectos del movi- miento moderno, tengo que decir que mientras que Le Corbusier es innegablemente brillante, es Mies al cual le tengo más simpatía ${ }^{46}$. La diferencia con el maestro es que Pawson reconoce su condición de prestidigitador al aceptar que su condición visual mínima de hacer (casi) nada no es siempre sinónimo de poco esfuerzo. La simplicidad en la arquitectura puede ser conseguida a veces solo a través de los medios más complejos. Un material monolítico como una pieza sólida de mármol tiene una gran simplicidad intelectual. Pero debe ser dicho que trabajarla implica una enorme y compleja cantidad de organización. La aparente simplicidad de dichos materiales es simplicidad material solo desde un punto de vista visual ${ }^{47}$.

Esta posición tan sincera le aleja de esa ocultación de cantidades que suponía la arquitectura de Mies, sin embargo le afirma en esa posición del minimalismo como otro exceso más tal y como lo exponía Wigley. Y lo más importante lo aleja totalmente de ese minimalismo extremo -o de tendencia a cero y no al infinitoen el que realmente se incluirían los personajes perezosos que en este texto interesan.

También existen falsas cantidades en lo que el arquitecto inglés Jeremy Till define y critica como austeridad y escasez. Esta corriente surge como respuesta a la fiesta del exceso que ha vivido la arquitectura occidental, como una respuesta dentro de la época actual de recesión económica.

Así, unos cuantos estudios de arquitectura europeos son defendidos en las páginas de publicaciones como The Architectural Review, Building Design, 2G, y Detail como portadores de sentido común: Caruso St John, Tony Fretton y Sergison Bates en el Reino Unido, Peter Märkli y Valerio Olgiati en Suiza, Robbrecht \& Daem y Stéphane Beel en Bélgica, por nombrar sólo algunos. La mayoría 
de los edificios diseñados por estas firmas no son exactamente austeros, al menos en el sentido financiero; y por lo general solo aspiran a una estética minimalista del decoro y la rectitud tectónica en contraste con lo que ahora parecen las baratijas de la última década ${ }^{48}$.

Redunda esta posición en la situación anterior del minimalismo, en la que una imagen mínima que parece haberse hecho con muy poco conlleva realmente una cantidad de medios y esfuerzos considerables. Se produce el mismo desfase y engaño en las cantidades.

\section{ALGUNOS (SOLO ALGUNOS) BARTLEBYS ARQUITECTÓNICOS}

De todos los autores previos y sus textos acerca del hacer casi nada/pereza se desprenden algunos nombres -no están todos los que son pero sí son todos los que están- como posibles referentes arquitectónicos de esos personajes perezosos pertenecientes a la citada sociedad secreta. Casi siempre son otros los que les consideran como Bartlebys, ellos mismos tienden a mostrar vaguedad acerca de su conocimiento al respecto: No conocía al personaje de 'Bartleby'... ${ }^{49}$.

Ábalos descubre a Lacaton \& Vassal:

\section{[...] Formados en África-donde ecología} y economía significan supervivencia-decidieron que "preferirían no hacerlo» ante el encargo de remodelar la plaza de Léon Aucoc de Burdeos (1996), agradable para sus usuarios y suficientemente urbanizada, dedicando parte del presupuesto a renovar su gravilla, reparar sus bancos, sustituir algún bordillo-¿por quéhayque hacer algo espectacular, qué culpa tienen los ciudadanos?, se preguntaban-. No era gran cosa pero la satisfacción de los vecinos era enorme... ${ }^{50}$.

Reyner Banham descubre a Cedric Price:

Me encantaría que hubiera más Cedric Prices, aunque no sé si el mundo podría soportar más Cedric Prices - quiero decir, creo que una de las razones por las que es eficaz es debido a su status de 'Super Star 'y que no hay nadie que se le parezca-ya que su acercamiento a los proyectos es $\sin$ duda algo que llama la atención, pues no parte de decir: ¿qué tipo de edificio quiere usted?, sino de preguntar antes de nada, ¿Necesita usted realmente un edificio ${ }^{51}$.

Mark Wigley insiste en Cedric Price:

Price se convirtió en el gran sacerdote de hacer casi nada, de decir no cuando fuera necesario. Trabajando en secreto en su polémicamente vacía habitación blanca, reduciendo cada concepto y dibujo hasta el número mínimo de líneas y palabras, fue capaz de desafiar nuestra comprensión de la cantidad. Sin miedo a proponer nada o solo algunas soluciones temporales, mientras que otros proponían monumentos. Sus diseños eran casi nada ${ }^{52}$.

Esta es solo una pequeña muestra, a estos personajes les acompañan muchos más y todos juntos conforman una constelación arquitectónica que prefiere no hacerlo. Por desgracia, muchos de ellos siguen prefiriendo, y debemos respetarlo, mantenerse instalados en su sociedad perezosa secreta. 


\section{NOTAS}

1 Melville, Herman. Bartleby el escribiente (1853). Valencia: Pre-textos, 2000.

2 Deleuze, Gilles. Bartleby o la fórmula, en Preferiría no hacerlo: Bartleby el escribiente de Herman Melville, seguido de tres ensayos. Valencia: Pre-textos, 2000. p. 57-92.

3 Agamben, Giorgio. Bartleby o de la contingencia, en Preferiría no hacerlo: Bartleby el escribiente de Herman Melville, seguido de tres ensayos. Valencia: Pre-textos, 2000. p. 93-136.

4 Pardo, José Luis. Bartleby o de la humanidad, en Preferiría no hacerlo: Bartleby el escribiente de Herman Melville, seguido de tres ensayos. Valencia: Pre-textos, 2000. p. 137-192.

5 Deleuze, Gilles. op. cit. p. 62.

6 Barthes, Roland. Atrevámonos a ser perezosos, en El Grano de la voz. Entrevistas 1962-1980 (1981). Buenos Aires: Siglo XXI Argentina, 2005.

7 Pardo, José Luis. op. cit. p. 148.

8 Goncharov, Iván. Oblómov (1859). Barcelona: Alba, 2002. Oblómov es la historia de un joven aristócrata ruso que se ha entregado a esa pereza dolorosa de la que hablan Barthes. Su reacción frente a la sociedad que le rodea, su rebeldía, es la negación pura y dura; se cruza de brazos de un modo casi nihilista en que las acciones no tienen ningún propósito final.

9 Agamben, Giorgio. op. cit. p. 113-114.

10 Bourriaud, Nicolas. Postproducción. Buenos Aires: Adriana Hidalgo, 2009. Nicolas Bourriaud ha definido postproducción como: [...] un término técnico utilizado en el mundo de la televisión, el cine y el video. Designa el conjunto de procesos efectuados sobre un material grabado: el montaje, la inclusión de otras fuentes visuales o sonoras, el subtitulado, las voces en off, los efectos especiales. [...] Desde comienzos de los años noventa, un número cada vez mayor de artistas interpretan, reproducen, re-exponen o utilizan obras realizadas por otros productos culturales disponibles, ese arte de la postproducción responde a la multiplicación de la oferta cultural, aunque también más indirectamente respondería a la inclusión dentro del mundo del arte de formas hasta entonces ignoradas o despreciadas. Podríamos decir que tales artistas que insertan su propio trabajo en el de otros contribuyen a abolir la distinción tradicional entre producción y consumo, creación y copia, readymade y obra original.

11 Fontcuberta, Joan. Por un manifiesto posfotográfico, en La Vanguardia. Barcelona: 11/05/2011. p. 6.

12 Ver concepto de invisibilidad en Castro Flórez, Fernando. Talkument: Para borrar la pizarra (contribución al vandalismo arquitectónico). Madrid: DPA ETSAM, 2014. p. 107-108.

13 Wigley, Mark. Towards a History of Quantity, en Bouman, Ole; Koolhaas, Rem; Wigley, Mark. Volume 2: doing (almost) nothing. Ámsterdam: Archis, 2005. p. 29. Traducción propia.

14 Bourriaud, Nicolas. op. cit. 2009. p. 42.

15 Ibíd.

16 Wigley, Mark. op. cit. Traducción propia. p. 29.

17 Barthes, Roland. op. cit. p. 349.

18 Le Breton, David. El silencio (1997). Madrid: Sequitur, 2001. p. 43

19 Ibíd. p. 32-33.

20 John Cage en Ransoo, Kim. Lao-tzu's Voids and Mies' 'Almost Nothing, en The "Art of building» (Baukunst) of Mies Van der Rohe. Georgia Institute of Technology: Atlanta, 2006. p. 183. Traducción propia.

21 Sala diseñada para absorber en su totalidad las reflexiones producidas por ondas acústicas o electromagnéticas en cualquiera de las superficies que la conforman (suelo, techo y paredes laterales).

22 Le Breton, David. op. cit. p. 14.

23 Infraleve es el término que creó Marcel Duchamp para definir aquello que es más que leve, el recuerdo de la presencia de algo que ya no está. El calor de un asiento que se acaba de dejar, el sabor del humo que queda en la boca al fumar, el sonido del roce de los pantalones al caminar, las puertas del metro cuando alguien pasa en el último momento, las caricias, el aire de París en una gota de cristal, un dibujo al vapor de agua, el aliento vital sobre superficies pulidas, vidrio, espejo, piano...

24 Ábalos, Iñaki. Bartleby, el arquitecto, en El País. Madrid: 10/03/2007.

25 Ibíd.

26 Shandys, también llamados portátiles, conjurados en 1924 en la desembocadura del río Níger y que adoptaron este nombre en referencia al dialecto de algunas zonas del condado de Yorkshire (donde Laurence Sterne, autor de Tristram Shandy, vivió gran parte de su vida), donde significa indistintamente alegre, voluble y chiflado

27 Aparte de exigirse un alto grado de locura, quedaron fijados los otros dos requisitos indispensables para pertenecer a esa sociedad: junto a que la obra de uno no fuera pesada y cupiera fácilmente en un maletín, la otra condición indispensable sería la de funcionar como una máquina soltera. Aunque no indispensables, se recomendaba también poseer ciertos rasgos que eran considerados como típicamente shandys: espíritu innovador: sexualidad extrema, ausencia de grandes propósitos, nomadismo infatigable, tensa convivencia con la figura del doble, simpatía por la negritud, cultivar el arte de la insolencia. En Vila-Matas, Enrique. Historia abreviada de la literatura portátil. Barcelona: Anagrama, 1985. p. 13.

28 López Ujaque, José M.; Salcedo. Esteban. Disciplinary 
indifference: an awkward interview with Anne Lacaton, en San Rocco 7: Indifference. Milán: San Rocco, 2013. p.42.

29 Bouman, Ole. Doing (almost) nothing is (almost) all right, en Bouman, Ole; Koolhaas, Rem; Wigley, Mark. Volume 2: doing (almost) nothing. Ámsterdam: Archis, 2005. p. 1. Traducción propia.

30 Wigley, Mark. op. cit. p. 28. Traducción propia.

31 Soriano, Federico. Cut \& paste. Madrid: Fisuras, 2012. p. 86 .

32 Wigley, Mark. op. cit. p. 29. Traducción propia.

33 Koolhaas, Rem. Imagining nothingness, en $S, M, L, X L$. Nueva York: Monacelli Press, 1995. p. 200. Traducción propia.

34 Camus, Albert. El hombre rebelde (1951). Buenos Aires: Losada, 1978. p. 17.

35 Soriano, Federico. 100 Hipermínimos. Madrid: Lampreave, 2009. p. 59.

36 García-Germán, Jacobo. Substracción, observación y documentación, en Estrategias operativas en el proyecto arquitectónico. Procesos, herramientas y protocolos. Madrid: UPM, 2010. p. 196-197.

37 Ibíd.

38 Wigley, Mark. op.cit. p. 29. Traducción propia.
39 Ibíd. p. 28.

40 Ibíd.

41 García-Germán, Jacobo. op.cit. p. 200.

42 Ibíd.

43 Ransoo, Kim. op. cit. p. 173.

44 Banham Reyner. On trial 6: Mies van der Rohe. Almost nothing is too much, en The Architectural Review 132. Londres: 1962. p. 126. Traducción propia.

45 Año de inicio del proyecto de la casa Farnsworth.

46 Pawson, John. Minimum. Londres: Phaidon, 2006. p. 9. Traducción propia.

47 Ibíd. p. 13.

48 Till, Jeremy. Scarcity contra Austerity, en Places Journal, 2012. Traducción propia. Recuperado el 26 de abril de 2015 de https://placesjournal.org/article/scarcity-contraausterity

49 López Ujaque, José M.; Salcedo. Esteban. op. cit. p.44.

50 Ábalos, Iñaki. op. cit.

51 Banham, Reyner. BBC Radio 4, 5 de noviembre de 1976. Traducción propia.

52 Wigley, Mark. op. cit. p. 31. Traducción propia. 


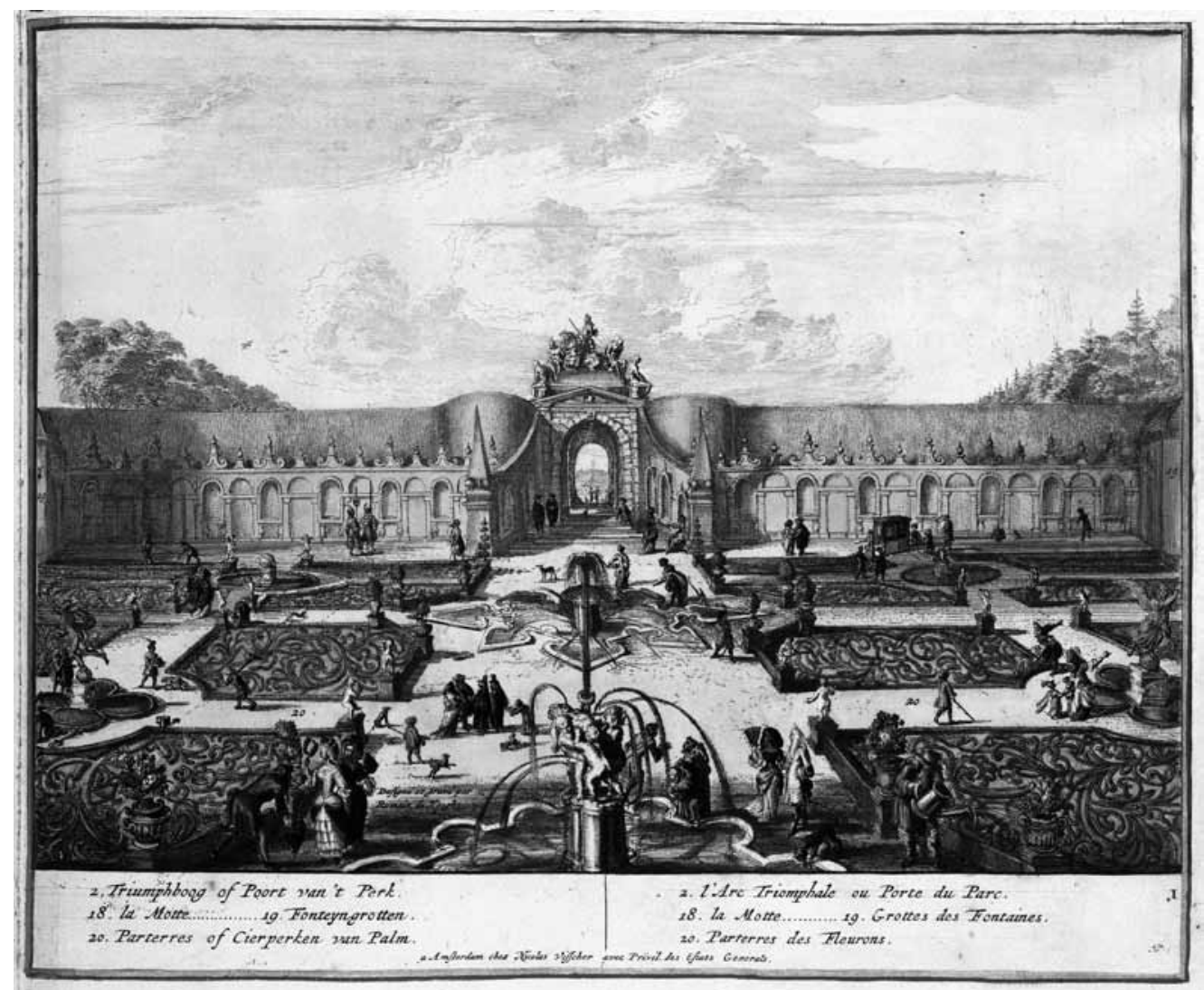

